\title{
IRON DEFICIENCY IN FREQUENT AND FIRST TIME FEMALE BLOOD DONORS
}

\author{
M. Boulahriss ${ }^{1}$ and N. Benchemsi ${ }^{1,2}$
}

Abstract:

\begin{abstract}
Back ground: Blood donation has a marked influence on the body iron stores especially in female blood donors . Iron deficiency anaemia is an important limiting factor for the number of donations in female regular blood donors.

Aim of the study: This study was conducted to evaluate the frequency of iron deficiency and relevant factors in frequent and first time female blood donors at Casablanca blood transfusion centre, Morocco.

Methods: Between November 2005 and April 2006, twenty-one female first time and twenty-one frequent female blood donors were selected randomly. In frequent blood donors, only females with at least 10 donations were included. Haemoglobin concentration, serum ferritin, serum iron and total transferrine binding capacity were measured and analysed.

Results: The results of haemoglobin concentration, serum ferritin, serum iron were significant lower in frequent female blood donors when compared with the results of same parameters in first time female blood donors. The results show that the frequency of iron deficiency in frequent female blood donors is $43 \%$ and in the first time female blood donors is $14 \%$.

Conclusion: Iron deficiency is very common in regular female blood donors at Casablanca's transfusion centre. Frequent blood donation has marked influence on the body iron stores in frequent female blood donors. It is therefore recommended that blood transfusion centres focused on maintaining iron balance by measuring serum ferritin and total transferrine binding capacity in frequent female blood donors. They have also to educate the donors about iron supplementation and yearly ferritin checking.
\end{abstract}

\section{Introduction}

Casablanca blood transfusion centre is the major organization involved in blood banking in Morocco and it collects blood from non-paid volunteers, of whom a considerable proportion donate blood frequently. Blood donation can lead to depletion of iron stores in the body. At each blood donation, approximately $213 \mathrm{mg}$ iron or $9 \%$ of the total iron stores in women are lost. With continuous loss of iron, the body adjusts to lower levels of iron storage or results in iron deficiency and anaemia (1).

About $28 \%$ of women in the reproductive age who donate just two times per year suffer from iron deficiency (2). If the lost iron stores in these donors are not replenished and they continue to donate blood, it results in iron deficiency anaemia and deferral of these donors in the future (3). Thus, a considerable number of regular donors who at present are the best source of safe blood are lost. In fact, iron deficiency anaemia is the main limiting factor in regular donors (1).

At present, there is no confirmed or specific programme for prophylaxis of iron deficiency in blood donors. In order to have such a programme, an evaluation of the present situation and accurate statistics of iron deficiency in blood donors is needed. Though most of the researchers have concluded that the frequency of iron deficiency anaemia increases with the number of donations (1,4-7), Birgegard and co-workers have reported that increased number of donations in women does not necessarily result in iron deficiency anaemia (8). There are non accurate statistics of frequency of iron deficiency anaemia in Moroccan blood donors, and it is not possible to use the results of studies in other countries for blood donors in Morocco. Therefore, this study was performed to determine the frequency of iron deficiency and its related factors in blood donors at Casablanca Blood Transfusion Centre.

Correspondence to: M BoulahrissRegional blood transfusion centre, Tel: 0021222 204588 , Fax: 0021222204589 ,

E-mail: crtscasa@menara.m

\section{Materials and Methods}

Between November 2005 and April 2006, we enrolled retrospectively a total of twenty one regular women blood donors who were selected according to the number of previous donations. Only female with at least 10 donations (3-4times per year) were included in frequent blood donors. The group of first time blood donors consisted of twenty-one women who were registered as new blood donors without any prior donation.

- All women were, healthy according to their history and fulfilled the criteria for suitability as blood donors.

- Data were collected by an interview and completion of a questionnaire.

After obtaining consent, personal information including age, pregnancy status, previous episode of haemorrhage and previous anaemia was entered and recorded for all donors under study

Two tubes of five millilitres blood were drawn from each case for measuring haemoglobin, serum iron, serum ferritin and Total transferrin Binding Capacity (TtBC). Samples were immediately carried out to the laboratory of haematology in EDTA tube for haemoglobin concentrations which were measured by cyanomet haemoglobin method using Coulter ${ }^{\circledR}$ GEN S ${ }^{\mathrm{TM}}$ System 2 automated and Pasteur Institute of Casablanca for Serum iron, Serum Ferritin and TtBC Concentrations.

Serum iron and TtBC concentrations were measured using VITROS 250 system chemistry automated analyser and ortho-clinical diagnostics kit. Ferritin concentrations were measured by the Immuno-Radio-Metric technique (IRMA) using IRMA-mat ferritin of diasorin kit.

\section{Haemoglobin and ferritin measurements}

- In this study, reduction in iron stores was defined as serum ferritin concentrations $<20 \mu \mathrm{g} \mathrm{L}^{-1}$;

- Lack of iron stores was defined as serum ferritin concentrations $<15 \mu \mathrm{g} . \mathrm{L}^{-1}$, and iron deficiency was 
defined as serum ferritin concentrations $<15 \mu g \mathrm{~L}^{-1}$, TtBC $>4 \mathrm{mg} \mathrm{L}^{-1}$ while anaemia was defined as haemoglobin $<115 \mathrm{~g} \mathrm{~L}^{-1}$.

- Iron deficiency anaemia was defined as serum ferritin concentrations $<15 \mu \mathrm{g} \mathrm{L}{ }^{-1}, \mathrm{TtBC}>4 \mathrm{mg} \mathrm{L}^{-1}$ and haemoglobin concentrations $<115 \mathrm{~g} \mathrm{~L}^{-1}$.

\section{Statistical analysis}

Groups of first time and frequent blood, donors were compared with each other using Student's t-test.

\section{Results :}

The population under study was divided into two groups:

- Group I: twenty one female first time blood donors.

- Group II : twenty one female regular blood donors, they donated three or four times a year and only women with at least 10 donations are included in this group.

- $\quad$ The age range was between 20 and 56 years with a mean age of $36 \pm 11$ years in group $I$ and between 22 and 62 years with a mean age of 40 \pm 10 years in group II.

- The percentage of blood donors with reduced iron stores (ferritin concentration $<20 \mu \mathrm{g} \mathrm{L}^{-1}$ ) showed an increase with increase in number of donations: about 19\% of first time female blood donors had reduced iron stores and this increased significantly ( $\mathrm{p}<0.000$ ) to $76 \%$ in regular donors (Table 1).

Table 1 : Distribution of donors according to iron stores and ferritinemia.

\begin{tabular}{lcccc}
\hline \multicolumn{4}{c}{ Iron stores } \\
\hline & $\begin{array}{c}\text { Normal } \\
\left(\text { Ferritin } \geq \mathbf{2 0} \mu \mathbf{g L}^{-1}\right)\end{array}$ & \multicolumn{2}{c}{$\begin{array}{c}\text { Reduced } \\
\left(\text { Ferritin }<20 \mu \mathrm{gL}^{-1}\right)\end{array}$} \\
\cline { 2 - 5 } & Women & $\%$ & Women & $\%$ \\
\hline Group I & $\mathbf{1 7}$ & $\mathbf{8 1}$ & $\mathbf{4}$ & $\mathbf{1 9}$ \\
Group II & $\mathbf{5}$ & $\mathbf{2 4}$ & $\mathbf{1 6}$ & $\mathbf{7 6}$ \\
\hline
\end{tabular}

The percentage of iron-deficient women (serum Ferritin concentrations $<15 \mu \mathrm{gL}^{-1}$ and $\mathrm{TtBC}>4 \mathrm{mgL}^{-1}$ ) increased with increase in number of donations. The frequency of iron deficiency was significantly higher in female regular donors (62\%) compared to first time donors $(14 \%)(p<0.001)$ (Table 2$)$.

Table 2: Distribution of blood donors according to iron deficiency.

\begin{tabular}{|c|c|c|c|c|}
\hline \multicolumn{5}{|c|}{ Iron deficiency } \\
\hline \multirow[b]{2}{*}{ Type of blood donors } & \multicolumn{2}{|c|}{$\begin{array}{c}\text { Absent } \\
{\text { (Ferritin } \geq 15 \mu g L^{-1}} \\
\text { and } T t B C \leq 4 \mathrm{mgL}^{-1}\end{array}$} & \multicolumn{2}{|c|}{$\begin{array}{c}\text { Present } \\
\text { (Ferritin }<15 \mu g L^{-1} \\
\text { and TtBC }>4 \mathrm{mgL}^{-1}\end{array}$} \\
\hline & $n$ & $\%$ & $n$ & $\%$ \\
\hline First time donors & 18 & 86 & 3 & 14 \\
\hline Regular donors & 8 & 38 & 13 & 62 \\
\hline
\end{tabular}

- Fourteen percent of first time blood donors suffered from iron deficiency anaemia while
$43 \%$ of women regular donors had iron deficiency anaemia (Table 3).

Table 3: Frequency of iron deficiency anaemia.

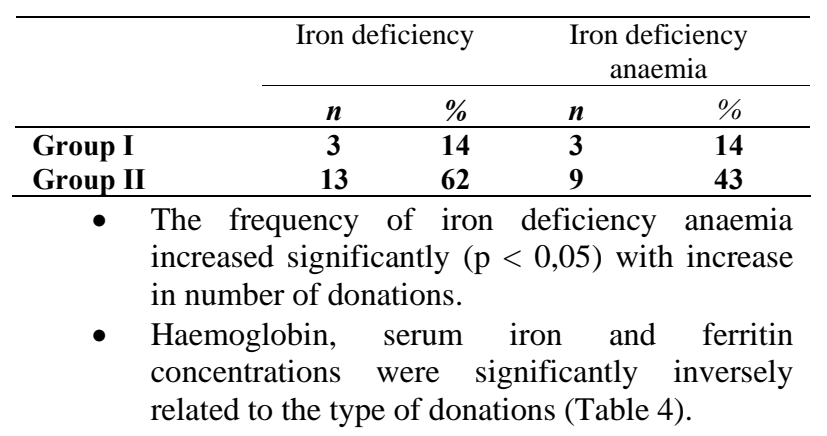

Table 4: Haemoglobin and iron status.

\begin{tabular}{lcc}
\hline & First time & Frequent \\
& $\mathrm{N}=21$ & $\mathrm{~N}=21$ \\
\hline Haemoglobin $\left(\mathbf{g . L}^{-1}\right)$ & $\mathbf{1 3 0} \pm \mathbf{8}$ & $\mathbf{1 0 0} \pm \mathbf{1 0 * *}$ \\
Serum iron $\left(\mathbf{g . L}^{-1}\right)$ & $\mathbf{0 . 7 0} \pm \mathbf{0 . 3 0}$ & $\mathbf{0 . 4 5} \pm \mathbf{0 . 1 5 * *}$ \\
Ferritin $\left(\boldsymbol{\mu g . \mathbf { L } ^ { - 1 } )}\right.$ & $\mathbf{3 2} \pm \mathbf{2 0}$ & $\mathbf{1 0} \pm \mathbf{8 * * *}$ \\
\hline
\end{tabular}

$(* * * \mathrm{p}<0.001) \quad(* * \mathrm{p}<0.01)$

- Serum ferritin concentrations showed the strongest relationship with the number of donations. The mean ferritin concentration in female first time blood donors was $32 \pm 20 \mu \mathrm{gL}^{-1}$ while in regular donors it was $10 \pm 8 \mu \mathrm{gL}^{-1}(\mathrm{p}<$ 0.001).

- Serum ferritin concentrations decreased with increase in number of donations.

- The frequency of reduced iron stores, iron deficiency and iron deficiency anaemia was higher in group II compared to group I. (p < 0.05) (Figure 1).

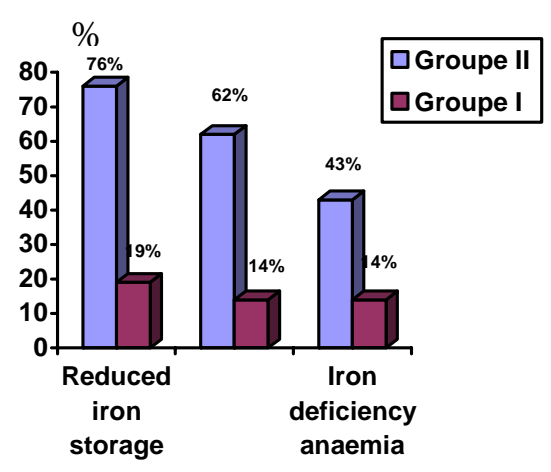

Figure 1: Distribution of both groups according to their iron storage.

\section{Discussion}

Serum ferritin concentrations had the strongest and most significant relationship with the number of donations compared to other laboratory investigations including haemoglobin and serum iron. 
Ferritin concentrations decreased significantly with an increase of the number of donations $(\mathrm{P}<0.001)$. Other studies confirm our findings (1,5,7,9-13).

As haemoglobin alone do not determine the iron storage levels of iron deficiency and considering the present findings, serum ferritin concentrations can be used as an indicator of the iron stores in blood donors. In the Iranian study $12.5 \%$ and $77.8 \%$ of first time and regular women blood donors respectively had iron deficiency (2). Other studies reported the same results (13-14). The present study showed that $14 \%$ and $62 \%$ of first time and frequent blood donors respectively had iron deficiency (Fig 1), which is similar to the findings of Javadzadeh and co workers in Iran.

In the present study $76 \%$ of regular women blood donors had reduced iron stores (Table 1) with mean ferritin concentrations in frequent blood donors $10 \pm 8$ $\mu g L^{-1}$ which was lower than the mean ferritin concentrations in first time blood donors $32 \pm 20 \mu \mathrm{gL}^{-1}$ (Table 4). We demonstrated in agreement with others (15-17) an increase of gradual iron depletion corresponding to frequency of blood donation.

About $62 \%$ of women regular donors had iron deficiency and $43 \%$ had iron deficiency anaemia. Iron deficiency and iron deficiency anaemia were seen in $77.8 \%$ and $55.6 \%$ respectively of women regular donors (2). Alvarez et al reported that $30 \%$ and $26 \%$ of women regular blood donors had respectively iron deficiency and iron deficiency anaemia (15). Cancado and Co-workers showed that $41.5 \%$ of women who had donated on several occasions had iron deficiency (14).

In our study the frequency of iron deficiency and iron deficiency anaemia in regular women blood donors are higher than the other studies (14-15) but less than the findings of the Iranian study.

These results could be due to the higher prevalence of iron deficiency in Moroccan and Iranian women populations due to the nutrition poor in iron.

\section{Conclusion}

Iron deficiency is very common in regular female blood donors at Casablanca's transfusion centre. Frequent blood donation has a marked influence on the body iron stores in regular women blood donors. It is therefore recommended that blood transfusion centers focused on maintaining iron balance by measuring serum ferritin in women frequent blood donors, they have also to educate the donors about iron supplementation and yearly ferritin checking, for that we propose a schedule to minimize iron deficiency and anaemic complications in women regular blood donors :
1. The routine measurement of ferritin for all first time female donors should be recommended in order to detect possible iron deficiencies before regular donations begin.

2. A ferritin screening procedure for all donors after the first ten donations might help to identify Iron-deficient women.

3. Iron supplementation after donations for all regular women blood donors with ferritin values $<15 \mu g L^{-1}$ should be considered.

As supplementation of iron not only increases the storage of iron in the donors but also leads the donor to donate blood in the future, it is suggested that research studies should be performed to determine the best method of iron supplementation with minimal complications.

\section{References:}

1) Finch CA, Cook JD, Labble RF \& Cuala M. Effect of blood donation on iron stores as evaluated by serum ferritin. Blood 1977, 50: 441-447.

2) Javadzadeh SH, Attar M \& Taher Y. A study of the prevalence of iron deficiency and its related factors in blood donors of Yazd, Iran, 2003. Transfusion Medicine 2005, 15: 287-293.

3) Simon TL. Iron, iron everywhere but not enough to date. Transfusion 2002 42:664-665

4) Bianco C, Brittenham G \& Gilcher RO. Maintaining iron balance in women blood donors of child-bearing age: summary of a workshop. Transfusion 2002, 42:799-806.

5) Garry PJ, Vanderjagt DJ, Wayne SJ et al. A prospective study of blood donations in healthy elderly persons. Transfusion 1991, 31:686-692.

6) Harthoorn-Lasthuizen EJ, Lindermans J \& Langehuijsen MM. Zinc protoporphyrin as screening test in female blood donors. Clinical Chemistry 1998, 44:800-804.

7) Simon T, Garry PJ \& Hooper EM. Iron stores in blood donors. Journal of the American Medical Association 1998, 245, 2038-2043.

8) Birgegard G, Hogman C, Killander A \& Wide L. Serum ferritin levels in male blood donors. Relation to number of phlebotomies and iron supplementation. Vox Sanguins 1987, 34: 65-70.

9) Badar A, Ahmed A, Ayub M \& Ansari AK. (2002) Effect of frequent blood donation on iron stores of non anemic male blood donors. J Ayub Med Coll Abdottabad 2002, 14:24-27.

10) Boulton F, Collins D, Inskip H, Paes H \& Garlick M. Study of the iron and HFE Status of blood donors, including a Group who failed the initial screen for anaemia. British Journal of Haematology 2000, 108:434-439.

11) Milman $N$ \& Sondergaard $M$ (1984) Iron stores in male blood donors evaluated by serum ferritin. Transfusion 1984, 24:464-468.

12) Milman $N$ \& Kirchhoff $M$. Influence of blood donation on iron stores assessed by ferritin and haemoglobin in a population survey of 1433 danishmales. European Journal of Haematology 1991, 47:134-139.

13) Nardrajan VS \& Eow GI. Anemia and iron status among blood donors in a blood transfusion unit in Malaysia. The Malaysian Journal of Pathology 2002, 2:99-102.

14) Canacado $R$, Chiattone $C \&$ Fausto $F$. Iron deficiency in blood donors. Sao Paulo Medical Journal 2001, 119: 4.

15) Alvarez-Ossorin L, Kirchner $H$, Kloter $H$ \& Schlenke P. Low ferritin levels indicate the need for iron supplementation strategy to minimize irondepletion in regular blood donors. Transfusion Medicine 2000, 10:112.

16) Garry PJ, Koehler KM \& Simon T. Iron stores and iron absorption: effects of repeated blood donation. The American Journal of Clinical Nutrition 1995, 62:611-620.

17) Ledue TB, Craig WY, Ritchie RF \& Haddow JE. Influence of blood donation and iron supplementation on indicators of iron status. Clinical Chemistry 1994, 40:1345-1346. 